quently followed more successful attempts to relieve hæmatometra, the operation being occasionally succeeded by intra-peritoneal hremorrhage. This, according to M. Bernutz-whose opinion is confirmed by Dr. Graily Hewitt and other more recent authorities-is due to the contraction of the uterus, set up by the evacuation of the fluid, continuing and forcing the blood contained in the Fallopian tubes into the peritoneal cavity. The risk of operating in such cases with cutting instruments in the interspace between the bladder and rectum without wounding either, as in De Haen's case, was referred to by Bernutz, "by way of warning against the employment of the knife in those cases instead of using the finger, as in the case related by Amussat. "The difference," he says, " in the relative mortality of these two proceedings has induced me to separate cases of congenital absence of the vagina, requiring the process of separating the parts by means of the finger from other cases of fibrous obliteration, congenital or acquired, in early life, for which the knife alone must be resorted to, although it is always under circumstances of extreme danger."

It should, moreover, be observed that in several instances in which no operation was attempted death had resulted from rupture of the distended Fallopian tubes, or of the uterus itself, and consequent extra-peritoneal extravasation, leading to fatal peritonitis or septicemia; as the following instance shows:-

R. S- aged eighteen, was in articulo mortis when seen first by Dr. Munck on Feb. 24th. For eighteen months she had suffered symptoms indicating the accession of menstruation, but without any results; these symptoms recurred periodically with increasing severity. After nine months a tumour appeared in the abdomen; it was very tender on pressure. On Feb. 20th she felt something give way, and the abdominal tumour disappeared. Severe pain followed, attended by a good deal of febrile disturbance; a blister was applied and a saline aperient administered; but she died in three days.

Post mortem examination. - On opening the abdomen twelve or fourteen ounces of thick reddish fluid were seen the peritoneum was highly congested, and traces of lymph were evident. The uterus was large but soft, and contained four or five ounces of fluid like that in the abdomen. The Fallopian tubes were enormously distended, the free extremity of the right being closed, and a rupture of about three lines in extent was seen, forming a free communication between the uterus and the cavity of the peritoneum through which the fluid had escaped. The vagina was closed by a firm cartilaginous membrane. ${ }^{7}$

Another similar case was subsequently reported by Dr. Gosselin, 8 who relates a case of absence of vagina, with retention of menstrual blood. An artificial vagina was made, and a large quantity of fluid evacuated. The patient died on the fifth day. A large quantity of chocolate-coloured fluid was found in the abdomen, and recent peritonitis; a tube had ruptured, giving exit to fluid into the abdomen. Cases such as those now referred to, whether original or quoted, are, I think, well deserving of consideration in illustration of two points of great practical interest. The first is the im. portance of an early diagnosis in such cases, so as to anticipate and prevent the occurrence of hrematometra that might lead to the rupture of the distended uterus or tubes. The second is the paramount necessity in all instances of operative interference of this kind of securing the permanent patency of a sufficient passage for the free external escape of the menstrual fluid, and thus obviate its possible intra-peritoneal extravasation through the Fallopian tubes. In the formation of an artificial vaginal passage it requires considerable caution, as already observed, whilst dissecting our way through the cellular tissue between the rectum and bladder, to avoid injuring one or other of these parts. Nor is it by any means always easy to either strike the cervical portion of the distended and globular uterus, or subsequently to maintain the permanency of the new canal. Bearing in view the occasional absence or imperfect development of the uterus and its appendages in cases of congenital deficiency of the vagina, as well as the risks of its attempted artificial formation by operation, it is hardly necessary to add that this should never be resorted to without previous evidence from physical examination of the existence of those organs, nor without the occurrence of symptoms of impeded or retained men-

7 Munck, Lond. Med. Gaz., vol. xxvii., p. 867, and Bemutz, op. cit. 8 Gaz. des Hôpitaux, 1867 . struation. The pros and cons with regard to operative interference in these cases have been tersely put by Dr. Graily Hewitt :- "There are, he says, two classes of cases to be dealt with: (1) Those in which the absence of the vagina is accompanied with signs of menstrual retention; and (2) those in which no signs of menstrual retention are present. This division is a practical one, for in the first class of cases operative measures are generally called for, while in the second this is not usually, or at all events necessarily, the case."9 In the former, by a properly conducted recto-vesical examination, the introduction of the sound in the latter and of the finger in the former, we may, I think, readily ascertain the extent of the vaginal malformation or imperfection; whilst the condition of the uterus and its appendages can in like manner be exactly mapped out under chloroform by a conjoint recto-abdominal bimanual exploration, the result of which will be further elucidated by the history of the case, the occurrence of menstrual molimina, and the development of the external sexual apparatus and mamma. If these all point to existence of hæmatometra dependent on non-development or obliteration of the vaginal passage, then there can be no question as to the necessity of operative interference. The mere existence, however, of the womb itself is not per se, in my mind, sufficient reason for surgical intervention in any case of congenital absence of the vagina, unless, as previously observed, we have in addition evidence of the menstrual secretion, and of its consequent retention in the uterine carity, where, by the nonpatency of its natural channel of exit, it is pent up and imprisoned, giving rise to the train of symptoms consequent on hrematometra. In no other case, in my opinion, should the formation of on artificial vagina be ever attempted. On that point I differ from Dr. Edis, ${ }^{10}$ who says, "Where the vagina is congenitally absent, and so interferes with the process of menstruation, coition, or parturition, it will be requisite to resort to operative interference to make a passage and to maintain this in a state of patency."

In the foregoing observations I have not attempted to consider the subject of acquired vaginal atresia or obliteration of the passage as a result of injury or disease. Having already sufficiently discussed these conditions in a former communication, I shall merely add that such obstructions are of more common occurrence than is generally thought, and that my experience is entirely in accordance with Spielberg's, ${ }^{11}$ that they most frequently result from previous puerperal endocolpitis. Neither have I here referred to those still more frequent cases of partial obliteration, or cicatricial occlusion, or atresia of the vagina that occasionally come before us in gynæcological practice, and of which, in the course of a quarter of a century's experience, I have met with some ten or twelve well-marked instances. In one of these, when I was consulted, this condition had led to the inception of proceedings for a decree of nullity of marriage; but, as in all other instances of the kind that have come under my observation, this cause of marital trouble proved amenable to treatment by gradual dilatation. ${ }^{12}$

Dublin.

\section{PNEUMOTHORAX IN AN APPARENTLY HEALTHY YOUNG MAN WITHOUT REALISED INJURY; TAPPING ; RECOVERY.}

By WALTER A. E. WALLER, L.R.C.P.LOND., M.R.C.S., HOXORARY MEDICAL OFFICER, ST. CROSS MOSPITAL, RUGBY.

C. C- The patient, aged sixteen, had never been laid up, except for an attack of rheumatic fever nine months previously. During this attack there was a mitral bruit, with very thumping action; but this all cleared up, and when examined for admission into a lodge of Foresters a month or so previously to his present illness he was found sound. On April 19th, 1889, being in his usual health, he went out brook-jumping in thin shoes, but did not get wet, and had no fall. After this he had a cold in the head, but

3 Diseases of Women, 3rd ed., p. 681. London, 1882 11 Text-book of Midwifery. Translated by Hurry. Yol. ii., p. 138. London, 1888 .

The Obstetrical Section of the Royal Academy of Medicine in Treland, Dec. $20 \mathrm{th}, 1889$. 
nothing more. On April 24 th he began to ail, aching all over \&c., but walked into Rugby to work-a mile and a half, with a steep hill each way. On the following day pain and fulness in the epigastrium were experienced, with short breath; but he walked to work, though having to rest twice in going up the hill. On the 26th he got up and walked into Rugby, but was so ill when he reached his work (grocer's cashier) that he was soon sent home in a cab. Next day I saw him at his house dressed, sitting on a sofa. He did not look ill, and talked of going to work again on the 29th (which would be Monday). Temperature normal. More perhaps from a habit of being on the safe side than because I expected much wrong, I had his coat and waistcoat off to examine his chest. Not being satisfied, I had him stripped. Inspection showed deficient movement of the right side of the chest. Auscultation revealed insufficient respiratory sound on that side, though the breathing was nowhere inaudible. No tube sounds and no ægophony were present, but there was a most peculiar and marked metallic echo over the front and back of the right side on coughing or speaking, and it did not seem that liquid was concerned in its production. Resonance all over the right chest was a little deficient, but fremitus was everywhere present. On April 28th the patient was in bed, with a temperature of $101^{\circ}$, but there was no pain. Next day, however, he was unable to sleep from violent pain situated low down and in front of the right chest. Physical signs were much the same. No friction sound to account for pain. The right chest was now rather more resonant than the left. Movement and respiration were more deficient. The curious metallic echo was as marked as before, and could now be produced by deep inspiration, as well as by coughing and speaking. Temperature $102^{\circ}$. The pain was much relieved by poultices and small doses of morphia. The tongue was thickly coated; there was some colourless, frothy, and muco-purulent expectoration. On the 30 th the temperature was $101 \cdot 6^{\circ}$, pulse 120 at least (weak), and general restlessness was marked. The breathing was very embarrassed, face ruddy, and the ears were becoming blue in colour. The right chest was fuller both above the clavicle and over the general surface; tongue was still thickly coated. The patient experienced great thirst.

The interest of the case as much as its gravity suggested a consultation, and Dr. Clement Dukes saw him with me on the same day. The outcome of our meeting as regards diagnosis was that we had an uncomplicated case of pneumothorax, probably traumatic in origin, and we proposed to give stimulant expectorants with opium and digitalis, brandy when necessary, tapping of the chest if improvement did not soon ensue. The day following the bowels were relieved after a good purge, and there was no alteration in the pulse. The patient slept two hours in the early part of the night. Chest signs much the same, with less expectoration. I made an exploratory puncture in the axillary line, but the needle soon got blocked, and was withdrawn. On May 2nd the patient slept a little. Pain distinctly paroxysmal in character round the right nipple. He was still able to expectorate some sputum with effort; movement of the chest was freer, but it had the appearance of having air under the skin. During the night the patient was in and out of bed on account of difficulty of breathing. On the 3rd he lay continually on his back. The opium in the mixture at first eased the pain, but no longer does so. He complained greatly of oppression over the epigastrium. I punctured the right chest with an ordinary hydrocele trocar; plenty of air was forced out, but no fluid. His voluntarily ex. pressed opinion, made the following day, was that yesterday's puncture saved his life. He passed a good night, and slept about five hours, and had no pain or dyspnca till the morning, when the metallic echo was not so distinct in the axilla, though much as before elsewhere. On the 5th the patient was quite comfortable in the upright position, and slept three hours in a chair. More fremitus was observed over the right side. On the 6 th the temperature was $996^{\circ}$, and the patient continued to improve. On the 8th he slept all night in bed. On the 10th he lay on his left side comfortably. The echo was heard chiefly at the angle of the scapula and towards the axilla; less at the base. The patient, on the 13th, continued to sleep well, but was very thin in the body generally. Very little expansion of the right lung took place, and the right base was still curiously tympanitic. The temperature was normal on the 17th, and the breathing comfortable. On the 30 th the patient walked to Rugby and back without resting going up the hill. The expansion of the lung was much improved. No stomach note at the right base, but ordinary resonance still more marked there. He eats, drinks, and sleeps well. The left lung is recovering its normal condition. Subsequently he had a slight relapse in the way of cough and feverishness, necessitating two days' rest in bed. The June days were hot, and I think he canght cold by postponing his exercise till the evening. He soon, however, went to work, and I have not heard of him since.

Rugby.

OX THE

\section{IMPORTANCE OF SECURING COAPTATION OF THE LIDS IN CERTAIN DISEASES OF THE EYE.}

BY CHAS. BELL TAYLOR, F.R.C.S. AND M.D. EDIN., SURGEON TO TIIE NOTTIYGHAII AND MIDLAND EYE INFIRMARY.

Some years ago 1 was asked to visit a lady who was suffering from the effects of severe concussion of the brain she had been insensible for weeks, and her eyes were wide open night and day. In consequence of this constant exposure the cornea of the left eye had become inflamed and ulcerated, and a similar condition in the right had caused such extensive destruction of tissue that there was no chance whatever of saving the eye. By securing coaptation of the lids and the use of topical remedies the left eye recovered, and the patient, whose strength was restored in time, has now excellent sight. I have since had a precisely similar case, one eye only being saved owing to the late period at which I was consulted. Another patient, only

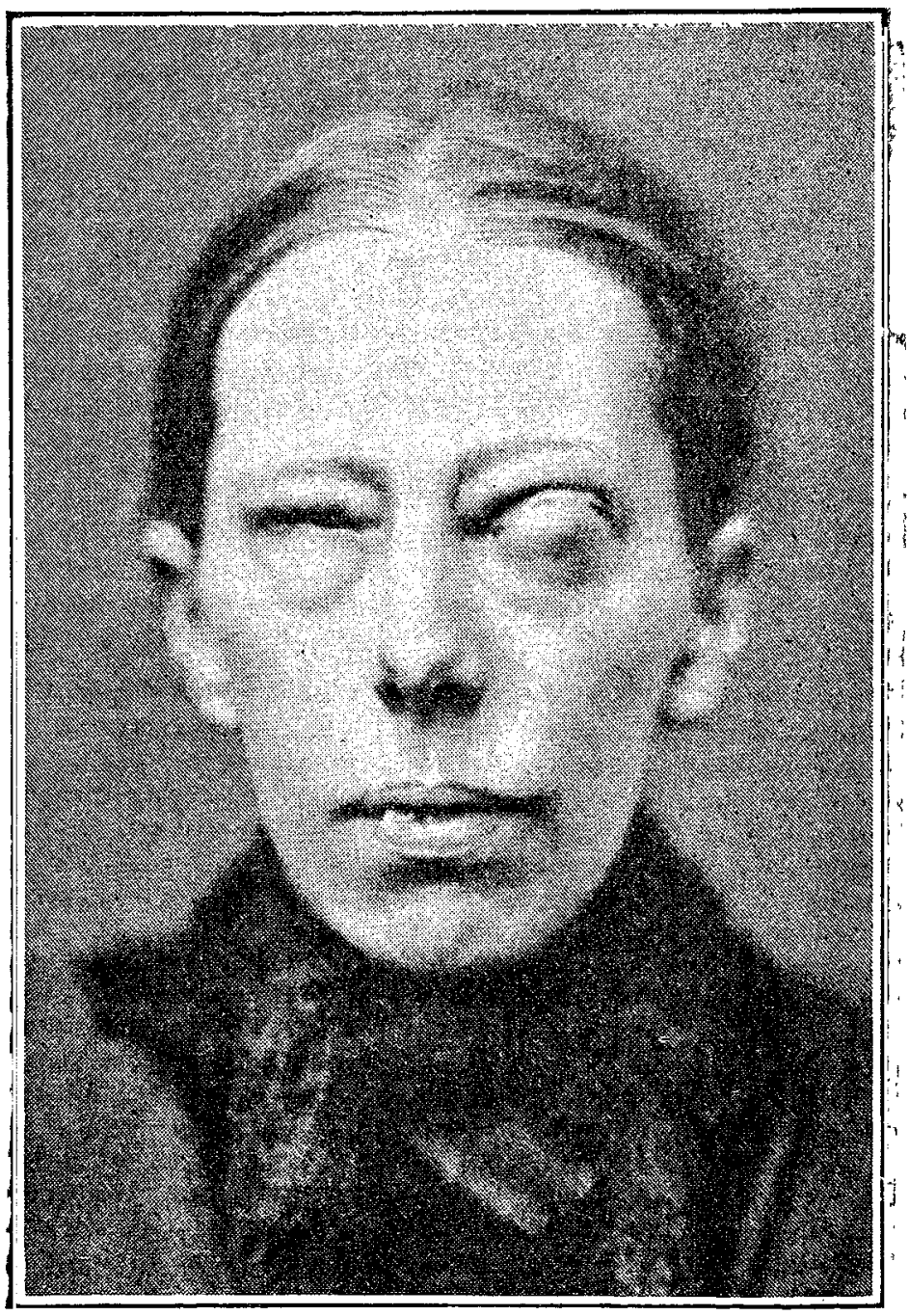

thirty years of age, who has lost both eyes from exposure, came under my care tive months ago suffering from breathlessness, palpitation, bronchocele, and great prominence of the eyes. Itreated her with compress bandages, galvanisation of the cervical sympathetic, and constitutional remedies for three months, and she was progressing very favourably when, owing to the expense of journeys to Nottingbam and 